\title{
Development workflow for virtual design of clothing for pregnant women
}

\author{
Katarzyna Cieśla1, ${ }^{1,}$ Iwona Frydrych1, Sybille Krzywinski², Yordan Kyosev² \\ ${ }^{1}$ Faculty of Material Technologies and Textile Design, Institute of Architecture of Textiles, Lodz University of Tech- \\ nology, Lodz, Poland \\ ${ }^{2}$ Faculty of Mechanical Science and Engineering, Institute of Textile Machinery and High Performance Material \\ Technology, Dresden University of Technology, Dresden, Germany \\ ${ }^{*} E$-mail address: katarzynaciesla7@gmail.com
}

\section{INFO}

CDAPT, ISSN 2701-939X

Peer reviewed article

2020, Vol. 1, No. 2, pp. $148-159$

DOI 10.25367/cdatp.2020.1.p148-159

Received: 30 June 2020

Accepted: 13 December 2020

Available online: 13 December 2020

\begin{abstract}
This study presents a workflow for the development of pregnant women's maternity dresses. It starts with the review of the main changes and requirements of the pregnant women. Using Blender, a special overlay is created, which can be added to the normal body and used for modelling of the different stages of the pregnancy. The pattern is created by Lectra ModarisV8R2 with connection to grading table. The 3D simulation is performed with Lectra 3D Fit for simulation and visualization. The result of the application of the workflow is a collection of pregnancy dresses in 4 sizes and tailored to each stage of pregnancy.
\end{abstract}

(C) 2020 The authors. Published by CDAPT.

This is an open access article under the CC BY-NC-ND license https://creativecommons.org/licenses/ peer-review under responsibility of the scientific committee of the CDAPT.

\section{Introduction}

Pregnancy is a time in a woman's life that requires special care and attention. Women are very sensitive at this time and overwhelmed by the new situation. The situation is so unique that the lifestyle can be completely transformed in order to provide the best possible conditions for the child. The changes in a woman's body are happening without her control, so that her attitude and well-being can change rapidly. The changes in the figure are so large that it is necessary to change the wardrobe, but the "new figure" does not exclude the possibility of looking good. Unfortunately, the range of maternity clothes on the market is mainly focused on clothes for typical figures.

While 3D CAD software are becoming more readily available in the apparel industry, it is important to continue to explore the possible and practical uses of these technologies in apparel discipline. Advantages of these programs are fast decision making, shortened development time and less physical 
samples reduced to one prototype. 3D CAD is able to replace design in different sizes and add physical properties of fabrics.

\section{Changes during pregnancy}

Medical literature and apparel field are good sources of information on body changes during the pregnancy. There are five changes during this period: of the body silhouette, size, posture, weight and psychological state. In several studies, the trimesters are used as single periods of pregnancy:

- $\quad$ first trimester - from conception to $12^{\text {th }}$ week,

- second trimester - from the $13^{\text {th }}$ week to the $28^{\text {th }}$ week,

- third trimester - from the $28^{\text {th }}$ week until the birth of the baby.

The first external physical changes appear at about month four, which is in the second trimester. All of these physical changes involve special care of comfort, fit and size in developing maternity garments [1].

\subsection{Body silhouette changes}

The period of pregnancy is related to rapid changes in the body size over a relatively short period of time. Every woman experiences this. External physical changes are most prominently seen in the bust and abdomen. They appear throughout the last two trimesters of pregnancy. For the purpose of studying the clothing, the last two trimesters are most important. The women at that time need clothing which accommodates these changes [1].

\subsection{Body measurement changes}

The changes are visible in the circumferences. Most women observe an increase from 20 to 26 centimeters around the waist. Abdominal extension varies because of the position of the fetus [1]. Some pregnant women carry their babies low and others carry their babies high. Sometimes the abdomen may seem to be pushed forward or hidden in their bodies [2].

Breasts also expand in size with an average of $5-8 \mathrm{~cm}$ circumference from the bust point at the fullest part of the bust [1].

Specific studies show that the waist, chest hip and high hip change are the most significant ones in pregnant women's body. The maximum value of chest circumference measurement is $125.23 \mathrm{~cm}$, while the minimum value is $86.90 \mathrm{~cm}$. There is a range of differences up to $38 \mathrm{~cm}$ and the maximum value is 1.44 times of the minimum. With regard to waist circumference, the maximum value was $120.85 \mathrm{~cm}$, while the minimum value is $83.82 \mathrm{~cm}$; the maximum value is 1.44 times of the minimum, which confirms that great changes also come to the waist. As to the high hip circumference (approx. $10 \mathrm{~cm}$ below waist), it is indicated that the maximum value of the measurement is $138.43 \mathrm{~cm}$ while the minimum value is $101.60 \mathrm{~cm}$, which makes the difference up to $36 \mathrm{~cm}$. Another data shows the maximum value of hip circumference measurement is $134.62 \mathrm{~cm}$ while the minimum value is $97.79 \mathrm{~cm}$, giving a difference of $36 \mathrm{~cm}$ and a multiple of 1.38 times. These data prove particularly a huge variation of these areas during the pregnancy [3].

\subsection{Posture changes}

During the pregnancy, the body weight balance must remain maintained. Abdominal expansion disturbs it. Because of this, the spine is temporarily curved to keep the body balance. This changes the body posture tilting it backwards. It happens in the second and third trimesters of pregnancy [1]. Changes in the posture, center of gravity, and gait cause discomfort such as a lower back pain, pelvic girdle pain, fatigue, and general malaise [4]. 


\subsection{Weight changes}

During a 40-week of pregnancy, a woman gains about 13 kilograms [1].

\subsection{Psychological changes}

Psychologically, the pregnancy is defined as a balance between positive and negative feel. Feelings switch rapidly from joy and exhilaration to fear and loss. Maturation and adaptation processes are simultaneous. Women may react with uncontrollable laughter or tears during daily events. However, emotional fluctuations are a normal reaction during pregnancy [2]. It may seem like the pregnant women feel bad about their body during the pregnancy. Research shows that the most of them have specific attitude to their body size. It turns out that the increasing girth does not bother women. Only the pregnancy is an exception to the rule. This can be influenced by the positive attitude of the community on this issue today. Moreover, women who have at least one other child feel better about their bodies than the first-time mothers [2].

It is worth noting that up to 80 percent of women feel uncomfortable with physiological changes. These discomforts can vary in the strength, from very weak to strong. This may lead to reduced functional mobility and disabling conditions during and post pregnancy [4]. Sometimes other people seem to stare at or try to avoid pregnant women. Such situations can make pregnant women feel uncomfortable and excluded from society [2].

Nine months of pregnancy turns out to be a tough time. Women have to face many discomforts and prepare themselves for the role of mother. Despite all the disadvantages, every mother recognizes this time as unique, extraordinary and wonderful.

\section{Maternity clothing}

Clothing plays a significant role in establishing and maintaining self-assessment. Indirectly, the appropriate clothing can help to maintain or redefine the self-worth in a positive way [2].

Due to all physical changes, women have to replace their old clothes with new ones. As it turns out, it is not so easy to find clothes that are comfortable during the whole pregnancy. Clothes that will fit in the $4^{\text {th }}$ month will not fit in the $9^{\text {th }}$ month. As a result, women are not sure how to fit their wardrobe. According to Burggraf, the moment when clothes become too tight for the most women is between 4 and 5 months. It is time to find suitable maternity clothes [1]. It is worth mentioning that young women are not ashamed of their pregnant belly and are even proud of it. Spacious clothes hiding the belly are out of date. Modern women want to underline it, but in a subtle way.

Shopping for well-fitting garments can lead to frustration for pregnant consumers. Moreover, the changes during the pregnancy among women are strongly varying [1]. Nowadays, women have the possibility to buy garments in the maternity size. Most literature recommends buying the maternity clothing in the same size as before the pregnancy. However, larger size can provide more comfort for some women [2].

The market for maternity clothes represents a very small part of the overall clothing market. Clothes for pregnant women can be bought mainly in specialty and department stores which assortment is not as varied in style and profitable as in other stores [2]. Women's quality and fashion requirements are the same during pregnancy as before the pregnancy. They want well-fitting apparel made of natural fibers [2].

\subsection{Design}

Consumers decide to buy clothes if they are properly fitted, so pregnant clothes design should focus on this. "However, research on everyday maternity clothing is scarce and there are no studies on maternity wear focusing on body shape changes during pregnancy" [1]. 
It is also important not to focus only on the size and shape. Design aspect should also include lifestyle and multidimensional comfort (thermo-physiological comfort, sensory comfort, comfort during the movement, and psychological comfort) [4].

Studies show that most women "prefer minimalistic and stylish garments, as well as practical rather than decorative and embellished garments. Maternity wear should look like non-maternity, but still be extremely functional for pregnancy" [4].

Nowadays, we need also reconsideration of maternity clothing design, because the number of obese pregnant women has increased over the last decades. They represent as much as $25 \%$ of all pregnancies [4].

\subsection{You are what you wear}

What we wear has power over our mood and others. Psychologists see a strong relation between clothing and mood. There is proof that we should wear not how we feel but how we want to feel. Even if we feel bad, the clothes we associate with happiness will be a good choice. We must be aware that the clothes we choose are sending a message also to us. It can make us feel powerful, in control or wealthy. So, if you are well-dressed, you are going to feel better about yourself [5].

\section{Observation}

Nine months is a small part of life. For pregnant women this period is so intense and unique that it stays in their memories for many years. Every woman more or less wants to go through this. New challenges and duties lead to transformation and prepare a woman to be a mother. Mental, physical and physiological discomforts are increasing and are tiring for them. Various thoughts and feelings appear constantly. This puts a woman in a poor mental condition.

Something that best defines a pregnant woman is a new figure. The silhouette of future mums changes dramatically. Apart from a constantly growing belly, the waist disappears, breasts grow and hips widen. The body weight increases by several kilograms. This is usually problematic for women, but becomes more and more often acceptable. Changes in the figure have an impact on physical symptoms. Increasing the body weight causes strain on the joints and a displacement of the center of gravity. The body is overloaded, which causes permanent pain.

New dimensions of figure also require new clothes. Wardrobe for pregnant women should meet the expectations of future mothers, ensuring aesthetic and functional comfort. There are few manufacturers of this type of clothing, which determines the small variety on the market. There is also very little research focusing on the clothing for pregnant women. Undoubtedly, this part needs a fresh look and improvement.

A pregnant woman during nine months of pregnancy encounters many dilemmas and difficulties. Normal, everyday issues during this time may turn out to be problematic. It is very important to reduce stress at this particular time and provide physical and mental comfort. Taking care of herself, avoiding worries, a woman has a positive influence on her own health and that of her baby.

\section{Purpose}

Taking into consideration the mental and physical condition of pregnant women and the 'power' of clothes, the goal of this study was to develop a dress in which they can feel better. The dress should make them feel attractive and elegant. Another idea was to create a garment that is universal and up-todate throughout the whole pregnancy period. Thanks to that, the product ensures psychological and functional comfort. 


\section{Modelling of the pregnant body geometry}

The body of the pregnant woman changes it geometry. For the modification of the body, the Blender software is used. This is a computer graphics software used for visual effects, arts, motion graphics, and interactive 3D applications. Using Blender, a 3D model can be created from scratch, sculpt, rig, texture, animate and render it to still or movie formats [6]. Blender can export to a variety of industry standard formats, including the .STL format and .OBJ format [7], so that it can be used in the clothing CAD software.

\subsection{Body avatars}

Starting point of our work were woman body avatars based on the SizeGERMANY portal [8] in sizes from 38 to 50. The SizeGERMANY portal presents the detailed results of German serial measurement. Within this project, serial measurements were carried out on 13,362 men, women and children between the ages of 6 and 87. From this, updated body dimension statistics, size tables and market share tables were developed and new findings for technical ergonomics were collected. Measurements were taken using the latest 3D body scanner technology [8]. The figures were the groundwork for creating a pregnancy figure (Fig. 1).

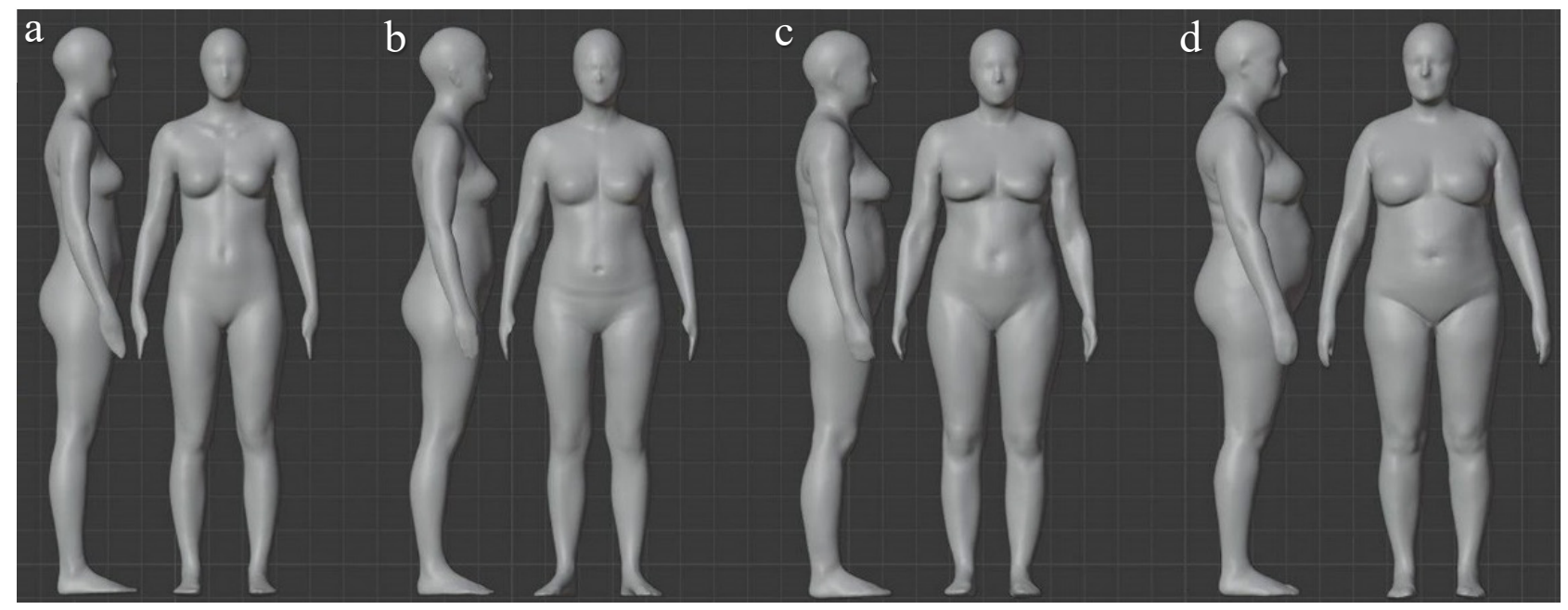

Fig. 1 Body avatars, side and front views: (a) size 38; (b) size 42; (c) size 46; (d) size 50 [8]

\subsection{Pregnant body avatar}

The source of the pregnant 3D model was a 3D Mag website [9], which contains 3D objects from scans and CAD software, normally used for 3D printing. This model was combined with the normal 3D models for the creation of the pregnant body (Fig. 2). Before that happened, several modifications on the body were done using Blender.

\subsection{Simplifying pregnant torso}

The removal of arms, breasts, back and legs made it easier to fit the figures later on (Fig. 3). This simplification is allowing the creation of something like an overlay that could fit into any figure. The most important body part is left, i.e. the abdomen and part of chest, to make it easier to orientate the whole piece. The removal of arms, breasts, back and legs made it easier to fit the figures later on. The breast size and shape was changed at a later research stage due to the complexity according to the dimensions in measurement tables [3]. 


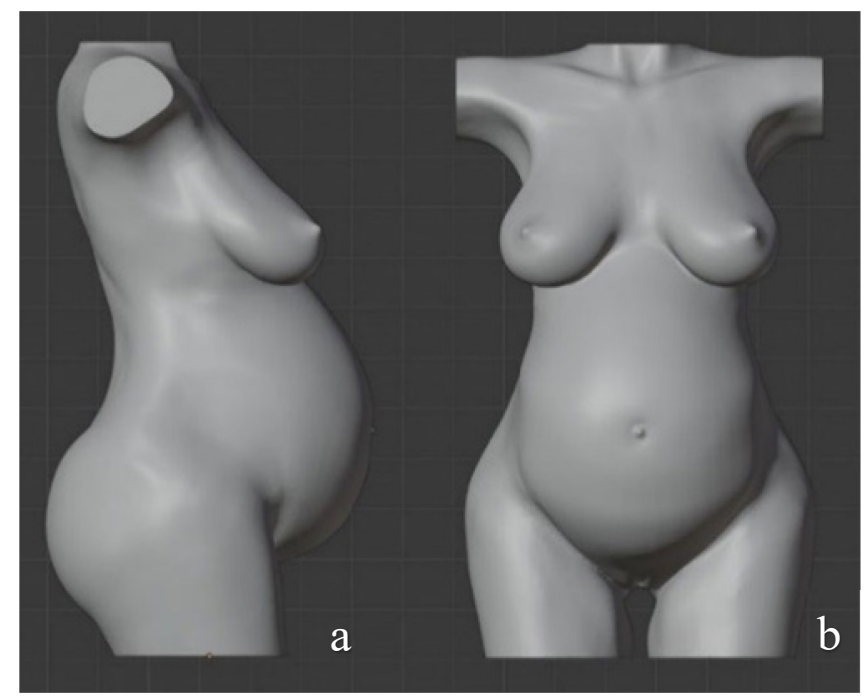

Fig. 2 Pregnant body avatar - 9 months of pregnancy:(a) side view; (b) front view [9]
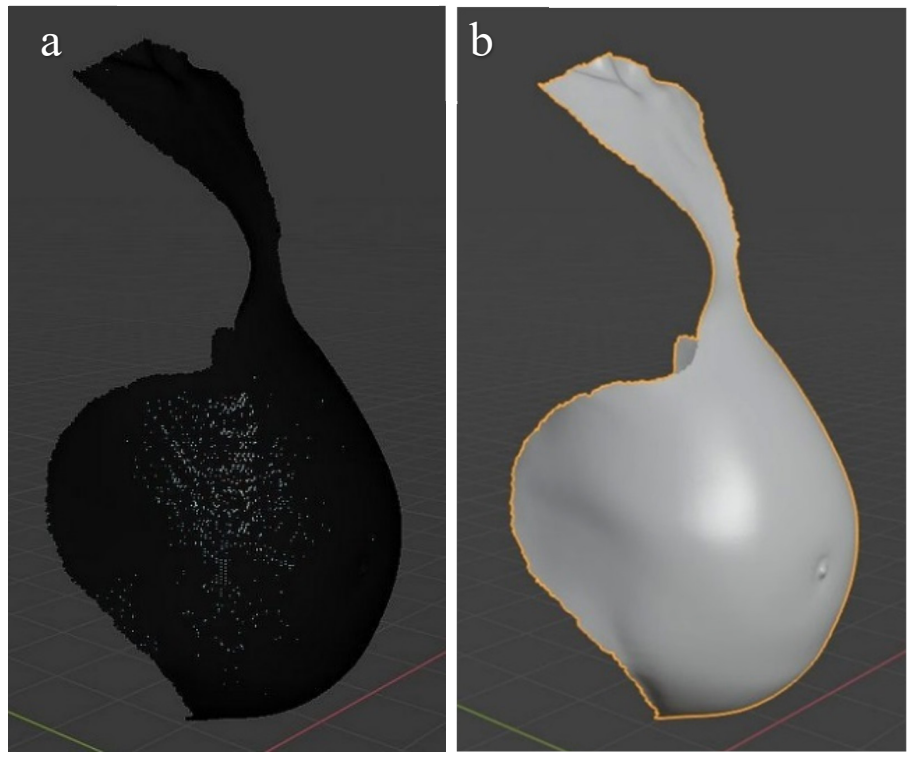

Fig. 3 (a) View in Edit Mode; (b) view in Object Mode.

\subsection{Union}

The next step was to merge the modified torso with the figure into one object. The abdomen has been permanently connected which is shown by the illumination around the silhouette which includes the abdomen (Fig. 4).

\subsection{Results}

The results of work in Blender are the figures of pregnant women in 4 sizes and in 3 different stages, as shown in Fig. 5:

- First stage - standard silhouette

- Second stage - half the maximum circumference of the pregnant abdomen

- Third stage - maximum abdominal circumference according to the table dimensions [3] 


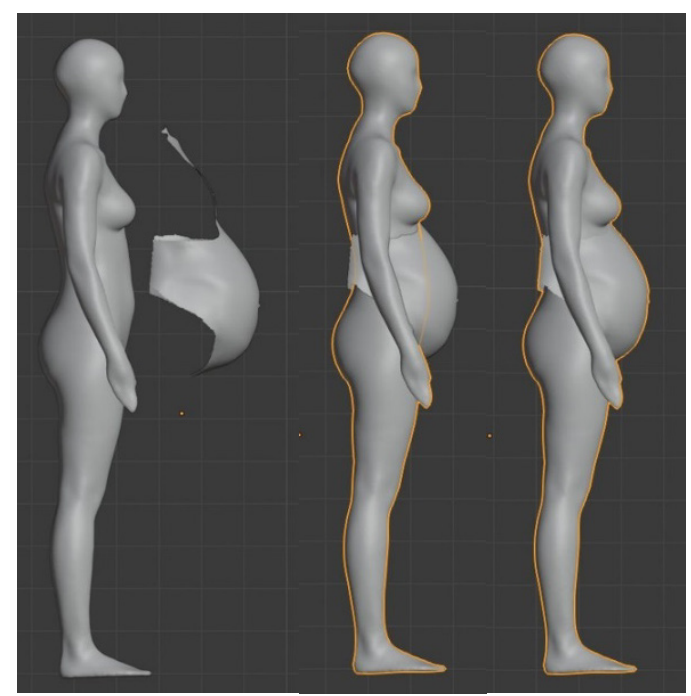

Fig. 4 Three stages of union
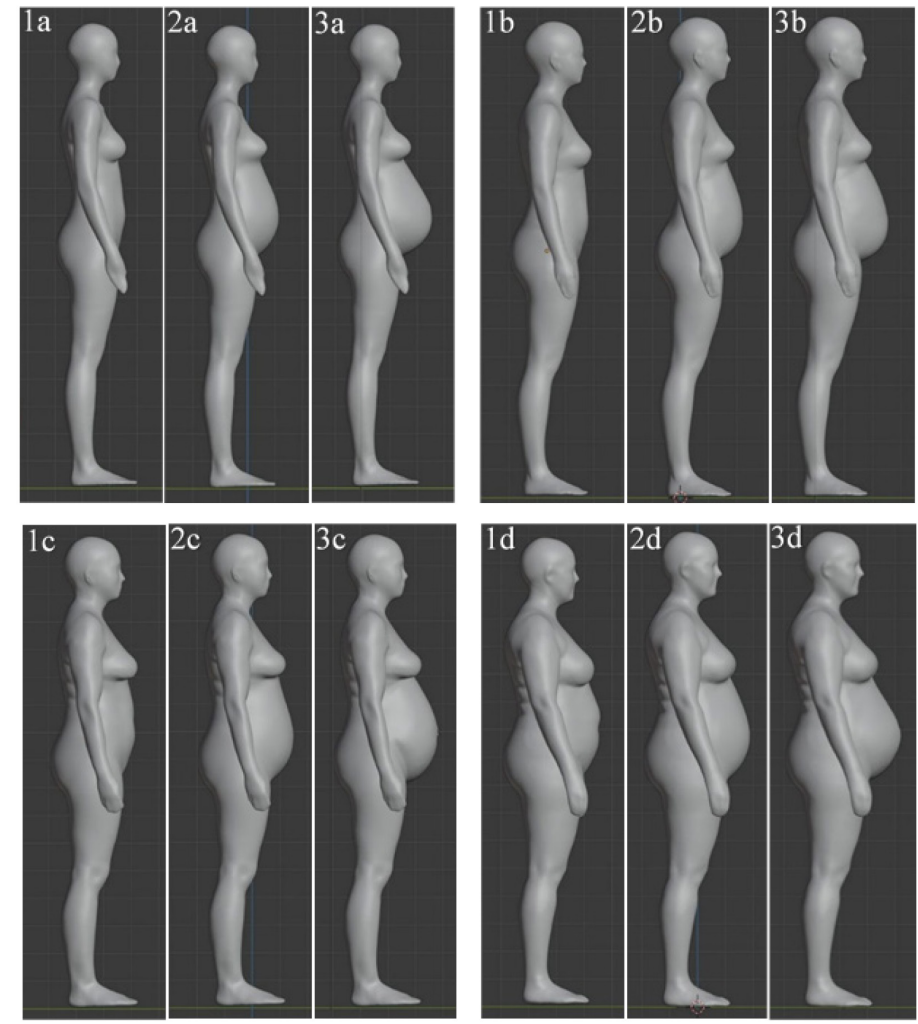

Fig. 5 Three stages of pregnancy: (a) size 38; (b) size 42; (c) size 46; (d) size 50

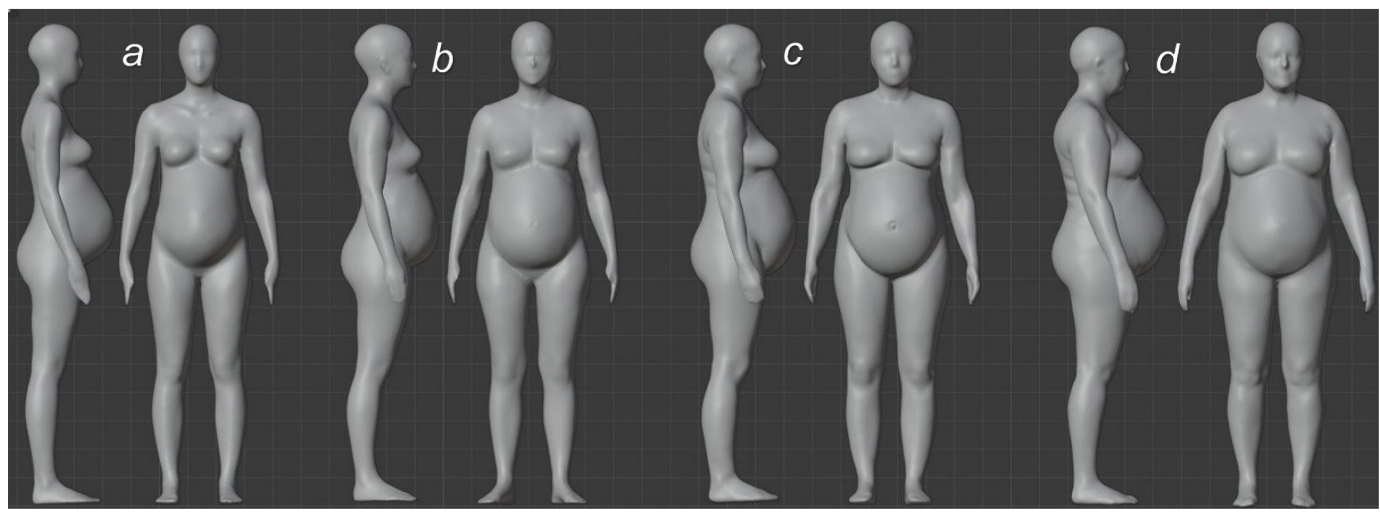

Fig. 6 Pregnant body, side and front view: (a) size 38; (b) size 42; (c) size 46; (d) size 50 


\section{Clothing Development with Lectra Modaris}

Lectra Modaris, Grafis, Assyst and Clo3D are the most used tools in the pattern production. For the current purpose, Lectra Modaris was used. The software is used for creating patterns in 2D for all garment types - lingerie, suits, men's and women's pants, children's wear, swimwear, uniforms, and work clothing. Additionally, the software has a digitalization and gradation option. All options are possible by using appropriate tools [10]. In this section, the setting up of the dress for the Virtual Dressing in Lectra 3D is described.

\subsection{Creation of Model Identification Sheet with size range and sheets for pattern construction}

The planned project is illustrated in the technical sketch (Fig. 7a and 7b). The project consists of two parts: a dress and a bolero. The model identification sheet was created (Fig. 7c), and a construction sheet was selected (Fig. 7d).
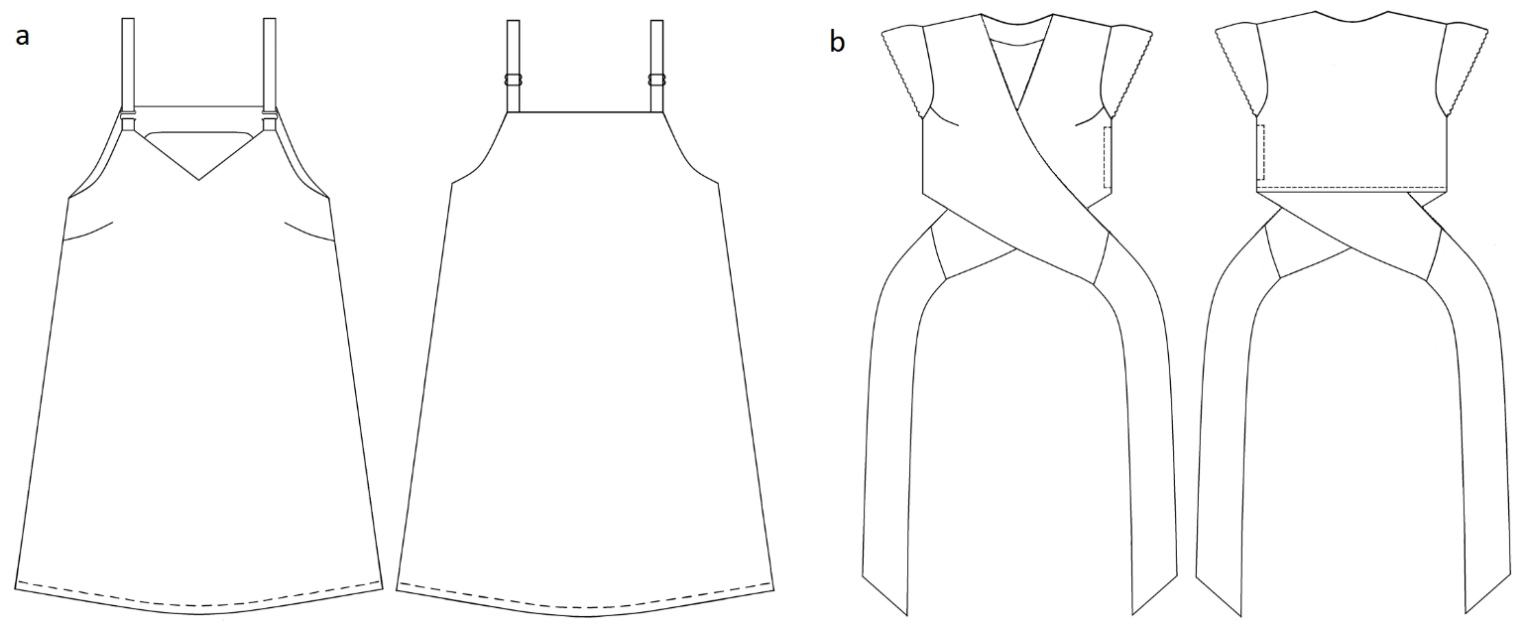

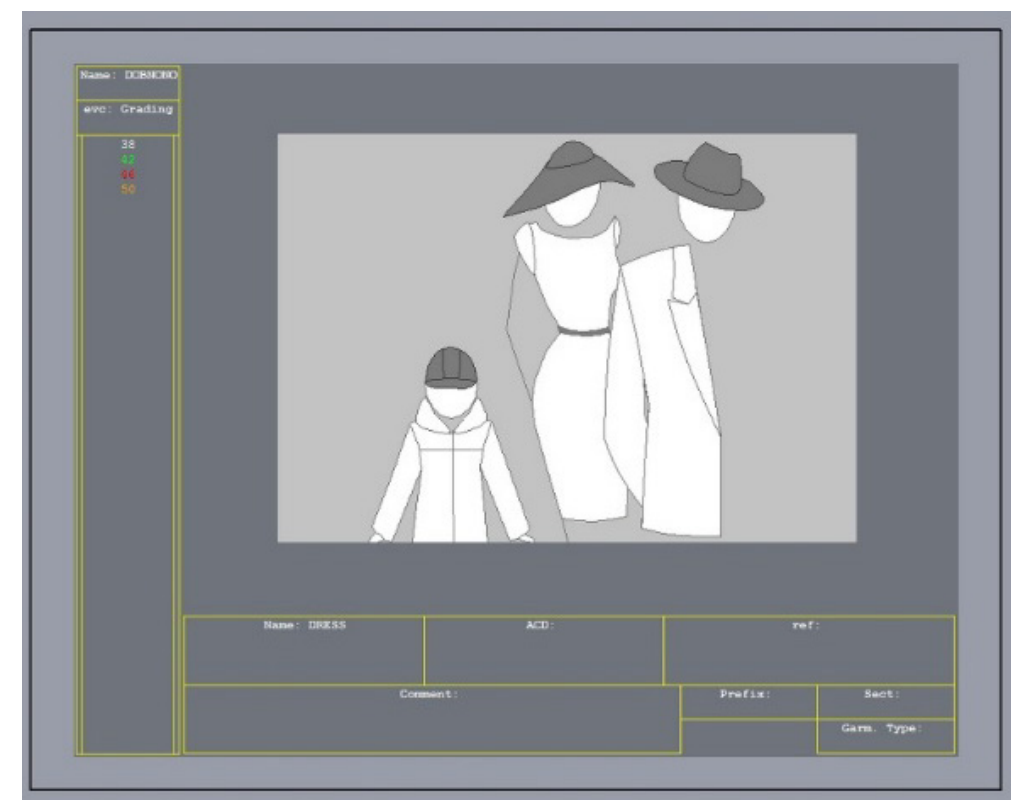

C

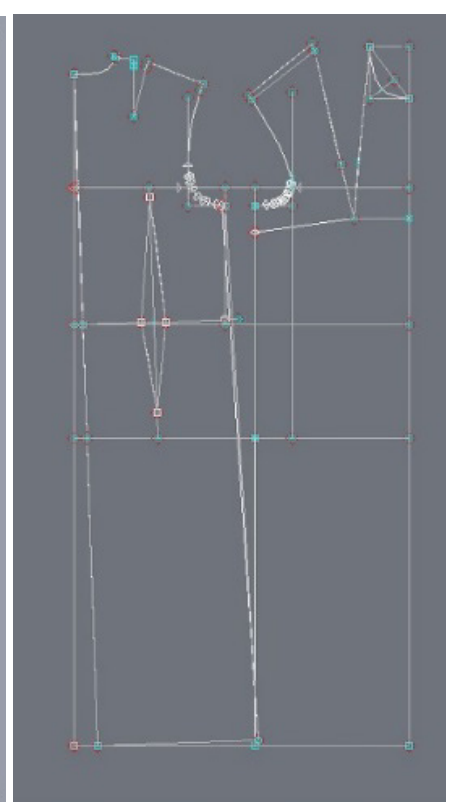

$d$

Fig. 7 Technical sketch of the project (a) front and back view of the dress (b) front and back view of the bolero (c) Model identification sheet; (d) construction sheet 


\subsection{Transform the shape outline into patterns}

The main modifications were made in the abdomen and bust area. To cover the abdomen, the patterns were extended at the waist and hip (Fig 8). The dress has shoulder straps. Additionally, a bolero covers the bust and is tied at the back. The bolero stripes are long enough to allow the user to adjust to the bust circumference. There are also elastic seams under the bust to ensure a better fit. The dimensions of the dress were adjusted to the figure at 9 months of pregnancy. The dress type ensures that it looks good on a figure with a small belly and a figure without a belly.

\subsection{Grading}

After the development of the pattern, these have to be graded, and for this task the key points have to be recorded as grade points. Each point was connected to its reference in a table, which enlarges or reduces the pattern automatically according to the predetermined direction. The values that were added were determined by the size table for pregnant women [3].

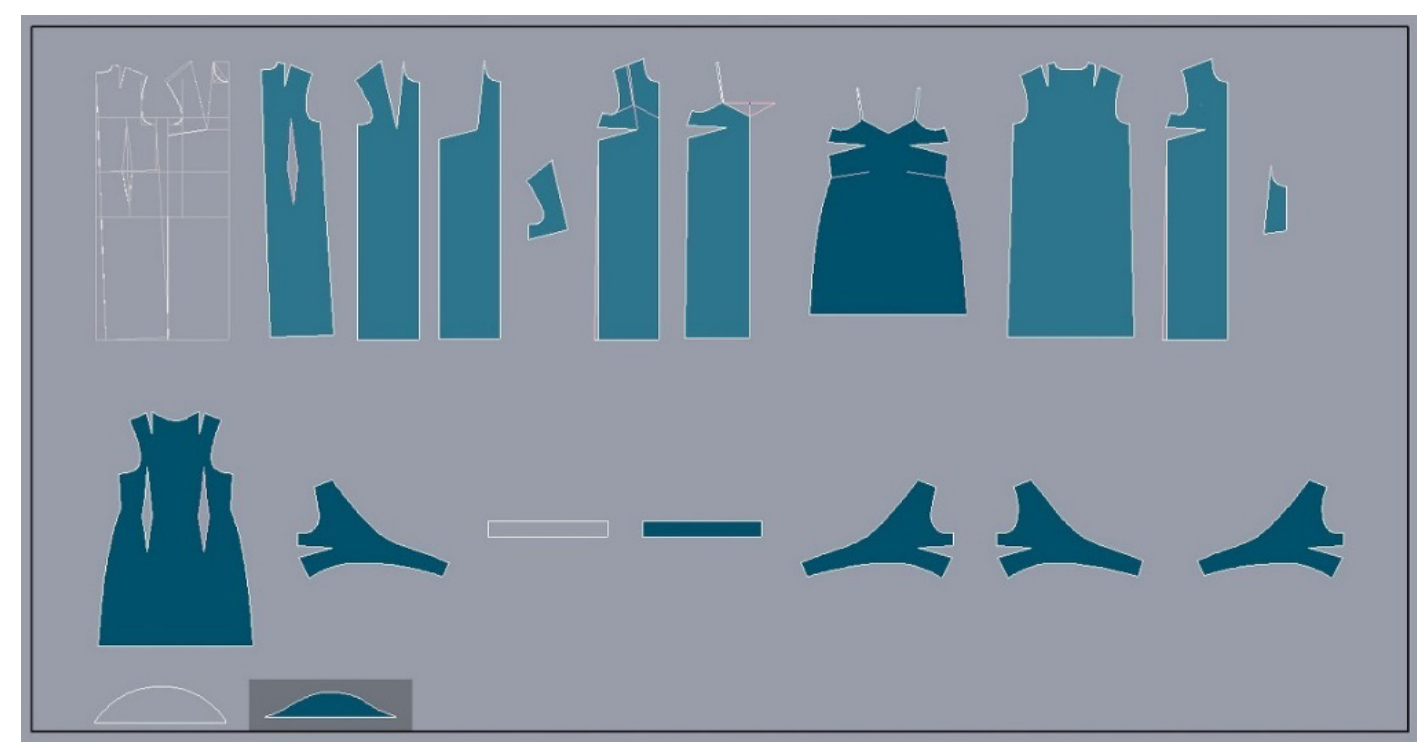

Fig. 8 All patterns in Lectra

\subsection{Creation of variants for the normal and pregnant and figure}

Based on the grading points, variants of normal and pregnant figure were created (Fig. 9). They differ only in the length of the bolero under the bust. 


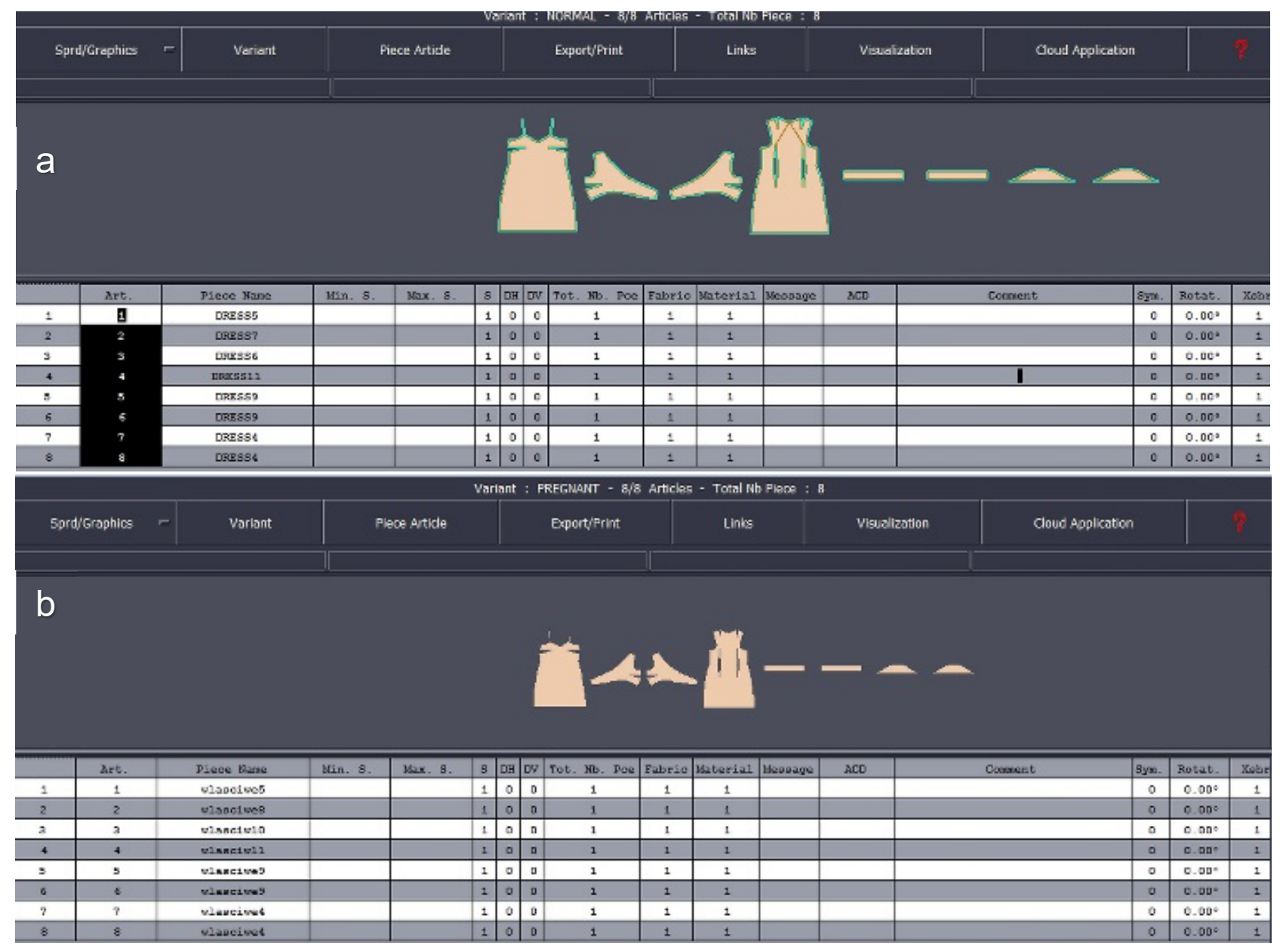

Fig. 9 (a) Variant for normal figure; and (b) variant for pregnant figure

\section{Fit simulation with Modaris 3D Fit}

Modaris 3D Fit enables to simulate and visualize models in 3D on a virtual mannequin, including the colors, motifs, and fabrics originally created in 2D. With Modaris 3D Fit, the look and fit of the garment can be verified, and its style. Virtual 3D prototyping ensures the quality of garment and its look and fit in all graded sizes and reduces the number of physical prototypes necessary to finalize a model [11]. An appropriate tool in the software Lectra 3D helps to sew together virtual patterns into final garment simulations. Lectra 3D allows visualizing the garment (Fig. 10). This gives the opportunity to take a closer look at the garment from all sides and see if any improvements are necessary. Thanks to this, it was possible to see how the dress fits on each figure and easily to assess if the product meets our expectations. 


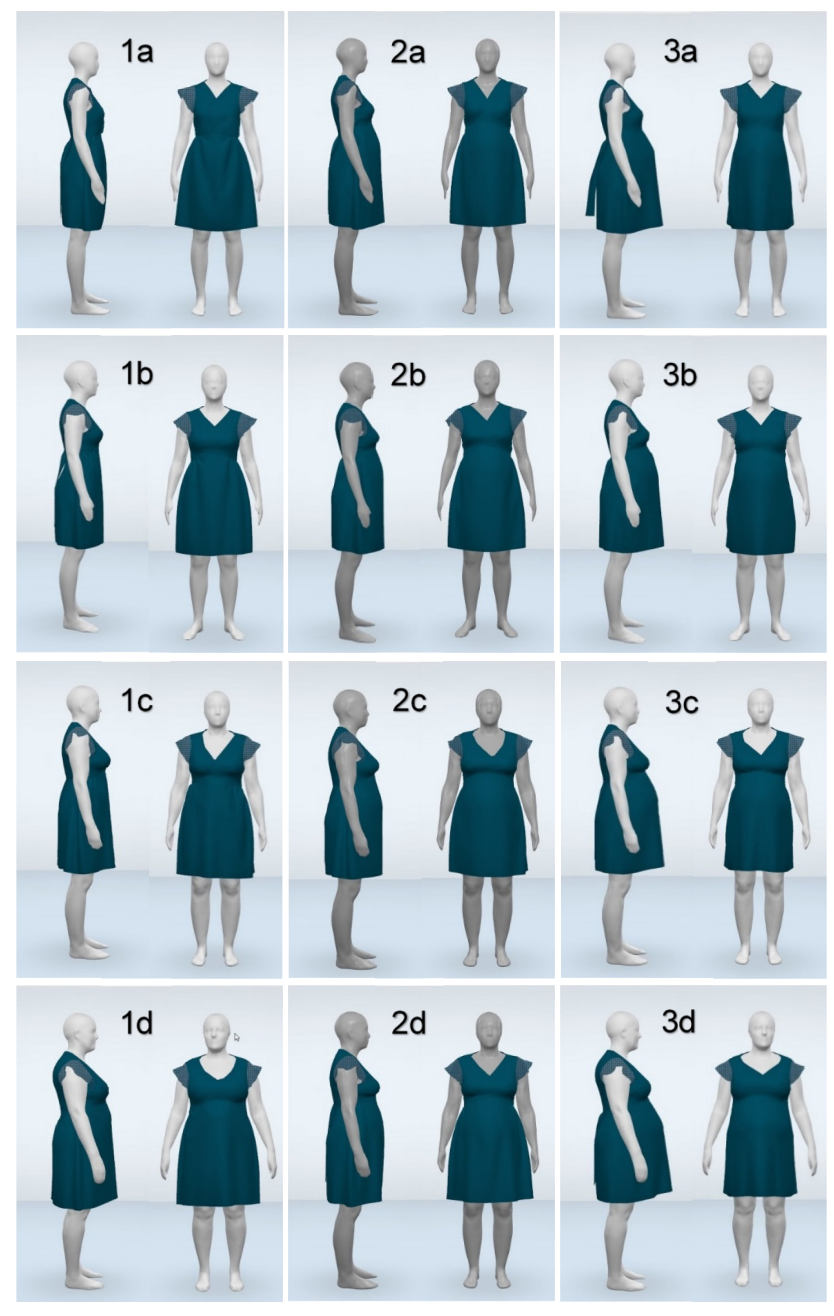

Fig. 10 Maternity dress in three stages of pregnancy: (a) size 38; (b) size 42; (c) size 46; (d) size 50

The style of the dress is minimalistic in order not to put additional weight on the body. The project has design solutions such as wrapped bolero and elastic seams for a better adaptation of the dress to the changing figure. The fabric used is thin and delicate, which will provide sensory comfort. The form of the dress is loose-fitting in order not to limit the movement. The dress is suitable for a casual use and elegant outing as well.

\section{Material selection of maternity dress}

Nowadays, the profile of pregnant women is fashionable and modern. They lead a high-quality life and pay attention to every single detail. This highlights how significant the pregnancy is and how excited women are about it.

Health and safety at this time are extremely important. Garments for pregnant women are also worth considering in this context. It is worthwhile selecting environmentally friendly materials and designing in the green natural way. Good examples would be organic cotton, soybean protein, silk and other materials, which have no additives and no pollution. Natural fibers are compatible with ecological environment and thanks to that do not harm the human body. In addition, these materials have the function of antiinflammation, anti-bacterial and protection against radiation. A basic and good choice is cotton. It is soft and feels comfortable even if the user has sensitive skin [12]. An important problem today is the radiation of electromagnetic fields, which can have a large impact on fetus development. As a result, there is research focused on the development of radiation-resistant fabrics. The material protecting the fetus 
against radiation is based on metal fibers containing $30 \%$ of them. A good example is also silver fiber fabric, which has anti-bacterial and skin-protection properties. Silk has great properties as well. Natural silk is able to smooth the skin, nourish body and heart and reduce stress for a better sleep. Mixing silk with silver fibers in appropriate proportion leads to fabrics with a soft touch and light texture. These fabrics are safe to put on and can be key part of garments during pregnancy [12].

\section{Conclusions}

Pregnant women are not a wide social group, but deserve an attention in their clothing. Their needs are strictly defined. There is only a lack of understanding and methods for the development of clothing for them. This work presents a development workflow, including all required steps during the development. This include modification of the human body geometry by meshing processing software Blender, modification of the pattern construction and its connection to a reference table for grading, creation of the different pattern and 3D fit simulation with Lectra 3D Fit. This workflow speeds up the development of collections for pregnant women and will help to fill the gap in the clothing market.

\section{References}

[1] Sohn, M. H. A pattern adaptation for body changes during pregnancy: a single case study. Master thesis, University of Minnesota, November 2009.

[2] Manley, J. M. Self-worth, body cathexis, and satisfaction with available selection for those who wear differentsize maternity clothing. Dissertation thesis, Virginia Polytechnic Institute and State University, May 1991. Available online: LD5655.V856_1991.M365.pdf.

[3] ASTM D7197 - 13, Standard table of body measurements for misses maternity sizes two to twenty-two (2-22), ASTM International. DOI: 10.1520/D7197-13.

[4] Quintero Rodriguez, C.; Anisimova, A.; Ryan, S.; Troynikov, O. Critical design aspects of maternity supportgarments and its contemporary perspective. KnE Engineering, 2017, 2 (1), 91-97. DOI: 10.18502/keg.v2i2.600.

[5] LearnVest. What your clothes say about you. Forbes, April 3, 2012. Available online: https://www.forbes.com/sites/learnvest/2012/04/03/what-your-clothes-say-about-you/ (accessed on February $17,2020)$.

[6] Blender 2.82 Reference Manual - Blender Manual. Available online: https://docs.blender.org/manual/en/latest/\# (accessed on February 27, 2020).

[7] Blender (software), Wikipedia, February 05, 2020 Available online: https://en.wikipedia.org/w/index.php?title=Blender_(software)\&oldid=939251869 (accessed on February 14, 2020).

[8] SizeGERMANY - Startseite. Available online: https://portal.sizegermany.de/SizeGermany/pages/home.seam (accessed on February 19, 2020).

[9] Pregnant woman torso free 3d model - download stl file. Available online: http://3dmag.org/en/market/item/3951/ (accessed on February 19, 2020).

[10] Stott, M. Pattern cutting for clothing using CAD: how to use Lectra Modaris pattern cutting software. Oxford: Woodhead Publ, 2012.

[11] Lectra Systems. Available online: https://www.sciencedirect.com/topics/engineering/lectra-systems (accessed on February 18, 2020).

[12] Shang, Y., Hu, X. Ergonomic maternity dress design. Procedia Manufacturing, 2015, 3, 187-191. DOI: 10.1016/j.promfg.2015.07.127. 